\title{
KEMAMPUAN SISWA MEMAHAMI BACAAN MELALUI FABEL
}

\author{
Jefrey Oxianus Sabarua'), Dewi Fatika Sari ${ }^{2)}$ \\ ${ }^{1,2)}$ Pendidikan Guru Sekolah Dasar, FKIP Universitas Halmahera \\ email:sabarua.jr@gmail.com : dewifatikasari@gmail.com
}

\begin{abstract}
Abstrak
Tujuan dari penelitian ini adalah untuk mendeskripsikan kemampuan membaca pemahaman siswa dan peran dongeng dalam pembelajaran di sekolah dasar GMIH Paca kelas tinggi. Penelitian ini adalah penelitian kualitatif dengan pendekatan fenomenologi. Data dalam penelitian ini mencakup data tentang kemampuan membaca pemahaman siswa dan peran dongeng dalam belajar dengan sumber data adalah 3 guru kelas tinggi, 30 siswa dan dokumentasi dalam bentuk nilai harian siswa. Data yang diperoleh diolah dan dianalisis dengan teknikanalisis deskriptif kualitatif.Setelah itu data dikurangi, disajikan dan disimpulkan.Hasil penelitian ini menyimpulkan bahwa: 1) siswa di kelas empat dan lima memiliki kemampuan membaca kurang, 2) ketidakmampuan membaca siswa disebabkan oleh pembelajaran monoton yang membuat siswa tidak menyukai pelajaran yang terkandung di dalamnya, 3) kreativitas guru kurang dalam menggunakan strategi pembelajaran yang dapat menarik perhatian siswa untuk belajar.
\end{abstract}

Kata kunci: KemampuanPemahamanMembaca, Fabel, trategiPembelajaran.

\begin{abstract}
The purpose of this research was to describe reading comprehension ability of students and the role of fable in learrning in the high class GMIH Paca elementary school. This research is a qualitative research with fenomenology approach. The data in this research include data on student's reading comprehension ability and the role of fable in learning with data sources are 3 high class teachers, 30 students and documentation in the form of student's daily grades. The data obtained was processed and analyzed by qualitative descriptive analysis techniques. After that the data is reduced, presented and concluded. The results of this study conluded that: 1) students in the fourth and fifth grades have poor reading comprehension ability, 2) the inability of student's reading comprehension is caused by monotonous learning that makes students dislike the lessons contained in it, 3 ) teacher's creativity is lacking in using learning strategies that can attract student's attention to learning.
\end{abstract}

Keywords : Reading Comprehension Ability, Fable, Learning Strategies.

\section{PENDAHULUAN}

Membaca merupakan

kemampuan yang penting dimiliki

oleh seorang anak karena

membaca merupakan jendela dunia. Melalui membaca kita dapat mengetahui berbagai hal (pengetahuan) yang ada di dunia ini (Sari \& Pandjaitan, 2017: 146). Membaca merupakan tuntutan 
dasar bagi anak yang baru masuk sekolah, karena semua pelajaran memiliki bahan bacaan dan anak harus dapat membaca hingga memahami isi bacaannya.

Menurut Broughton dalam Tarigan (2015: 45) membaca memiliki dua aspek penting yang harus dikuasai oleh anak yaitu kemampuan mekanik dan pemahaman. Rosyada (2004: 22) mengatakan bahwa sebagian besar anak Indonesia hanya dapat menguasai materi bacaan sekitar $30 \%$, selain itu mereka cukup kesulitan menjawab soal uraian yang membutuhkan penalaran.

Rendahnya pemahaman siswa dalam membaca dapat dipengaruhi beberapa faktor. Menurut Sumadoyo (2011: 20) ada faktor-faktor yang mempengaruhi kemampuan memahami bacaan siswa di antaranya: intelektual (berhubungan dengan IQ), kemampuan berbahasa (berhubungan dengan kosakata), psikologis (berhubungan dengan sikap, minat dan emosi), lingkungan (berkaitan dengan latar belakang sosial, ekonomi dan budaya), pengalaman (berkaitan dengan pengetahuan dan kebiasaan membaca). Dari sekian banyak hal di atas, yang dapat diasah di sekolah yakni pengalman anak tentang membaca. Semakin banyak pengalaman membaca yang dimiliki anak maka semakin baik pula pemahaman membacanya. Dalam hal ini guru dituntut untuk kreatif dalam penggunaan media pembelajaran dan strategi pembelajaran agar anak dapat merasa nyaman dan tertarik untuk belajar. Biasanya anak-anak di usia Sekolah Dasar sangat tertarik dengan cerita-cerita dongeng dan cerita hewan (fabel).

Seperti yang kita tahu bahwa di era modern ini, banyak orang yang mulai kehilangan minat dan ketertarikan terhadap sastra, dalam hal ini fabel yang dulunya sangat digemari oleh anak-anak usia sekolah dasar. Padahal dalam fabel terdapat banyak sekali pesan-pesan moral yang dapat diajarkan kepada siswa. Untuk mencoba mengembalikan ketertarikan siswa terhadap ceritacerita yang bermoral tersebut perlu adanya pembaharuan dalam pelaksanaan pembelajaran yang terkait dengan cerita moral (fabel). Di sinilah peran guru untuk mempersiapkan model pembelajaran yang sesuai dengan materi cerita fabel dan menumbuhkan kembali minat siswa terhadap materi tersebut.

Sekolah Dasar GMIH Paca adalah sekolah dimana pada saat studi awal, peneliti mendapatkan seorang guru kelas $\mathrm{VI}$ yang sering menyisipkan cerita dongeng dan fabel pada awal pembelajaran untuk membuat anak-anak tertarik belajar dan mereka sangat bersemangat untuk belajar setiap kali beliau mengajar dibanding guru lainnya. Sedangkan beberapa kelas lainnya cenderung lebih menyukai pelajaran matematika dibanding yang berkaitan dengan bahasa Indonesia dan guru kelas mereka jarang menggunakan fabel dalam pembelajaran bahasa 
Indonesia serta pembelajaran yang terkesan monoton membuat anak kurang tertarik dengan pelajaran bahasa indonesia maupun pelajaran lainnya yang memiliki bahan bacaan (IPA, IPS, dan PKn) sehingga hal ini kadang membuat anak keluar masuk kelas karena merasa bosan dengan pelajaran yang dibawakan oleh guru. Disini peneliti melihat bahwa betapa pentingnya membuat anak merasa tertarik dengan pelajaran yang guru sedang bawakan dan saat dibandingkan dengan anak-anak kelas VI yang lebih menikmati setiap pelajaran yang dibawakan gurunya karena cerita-cerita fabel yang beliau sisipkan di awal pembelajaran membuat anak antusias untuk fokus pada pelajaran yang sedang dibawakannya. Melalui fabel juga, beliau mengajarkan nilai-nilai moral, bagaimana berperilaku yang baik terhadap orang lain. Penelitian ini bertujuan untuk mengetahui kemampuan siswa memahami bacaan melalui fabel di kelas tinggi SD GMIH Paca.

\section{METODOLOGI PENELITIAN}

Penelitian ini menggunakan metode kualitatif deskriptif dengan pendekatan fenomenologi. Adapundata penelitian adalah data tentang kemampuan memahami bacaan dan peran fabel dalam pembelajaran dan sumber data meliputi 3 orang guru, 30 siswa (10 siswa kelas IV, 10 siswa kelas V, dan 10 siswa kelas VI) serta dokumen daftar nilai harian siswa tentang kemampuan siswa memahami bacaan.

Teknik pengumpulan data dalam penelitian ini adalah observasi, dokumentasi, dan wawancara. Data yang diperoleh dalam penelitian ini dianalisis menggunakan teknik analisis deskriptif kualitatif dengan tiga alur yakni: 1) reduksi data, 2) penyajian data, 3) penarikan kesimpulan.Kemudian diuji keabsahan datanya menggunakan triangulasi teori (Moleong, 2009: 324) dan menggunakan bahan referensi.

\section{HASIL DAN PEMBAHASAN}

Data yang diperoleh dianalisis dan diolah dengan teknik analisis deskriptif kualitatif. Data dalam penelitian ini berupa data hasil observasi checklist, wawancara dan dokumentasi.Hasil penelitian tersebut akan diuraikan satu persatu, sebagai berikut:

1) Kemampuan siswa memahami bacaan Kemampuan

memahami bacaan adalah kesanggupan seseorang untuk menangkap informasi atau ideide yang disampaikan oleh penulis melalui bacaan sehingga ia dapat menginterpretasikan ide-ide yang ia temukan, baik makna yang tersurat maupun tersirat dari teks tersebut. Mengukur pemahaman bacaan siswa tidak terlepas dari kecepatan atau waktu membacanya. 


\begin{tabular}{|c|c|}
\hline 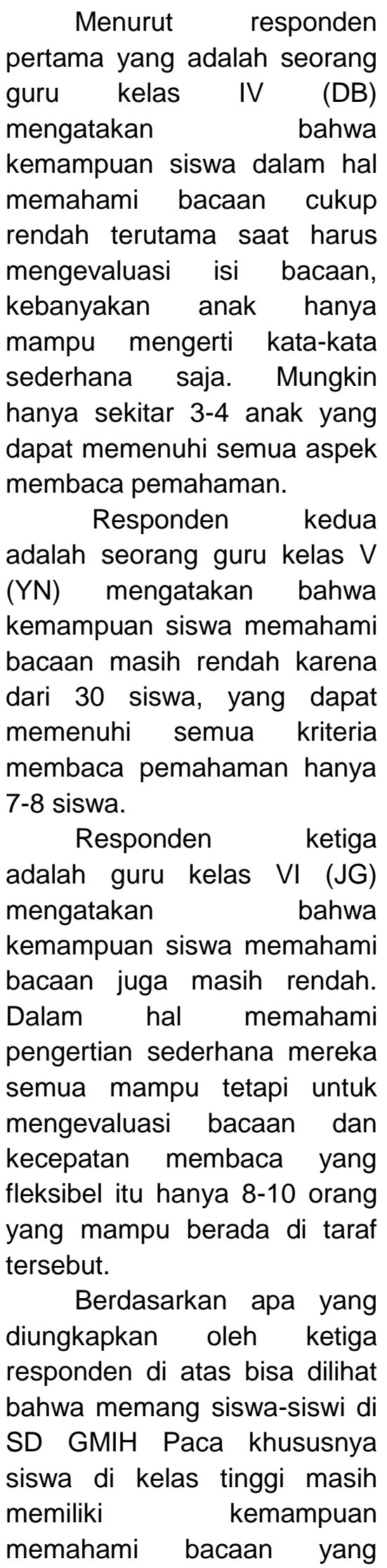 & 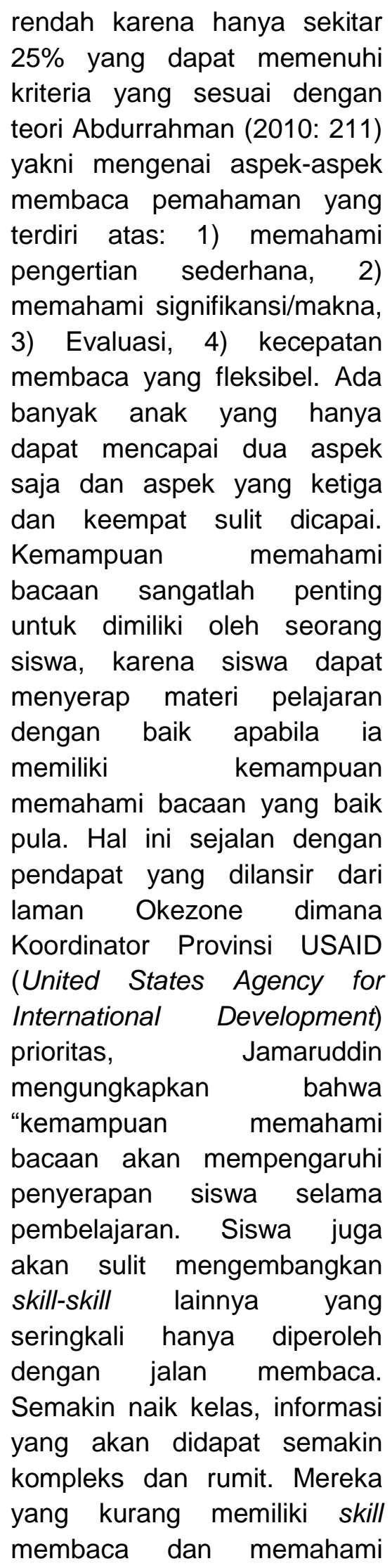 \\
\hline
\end{tabular}




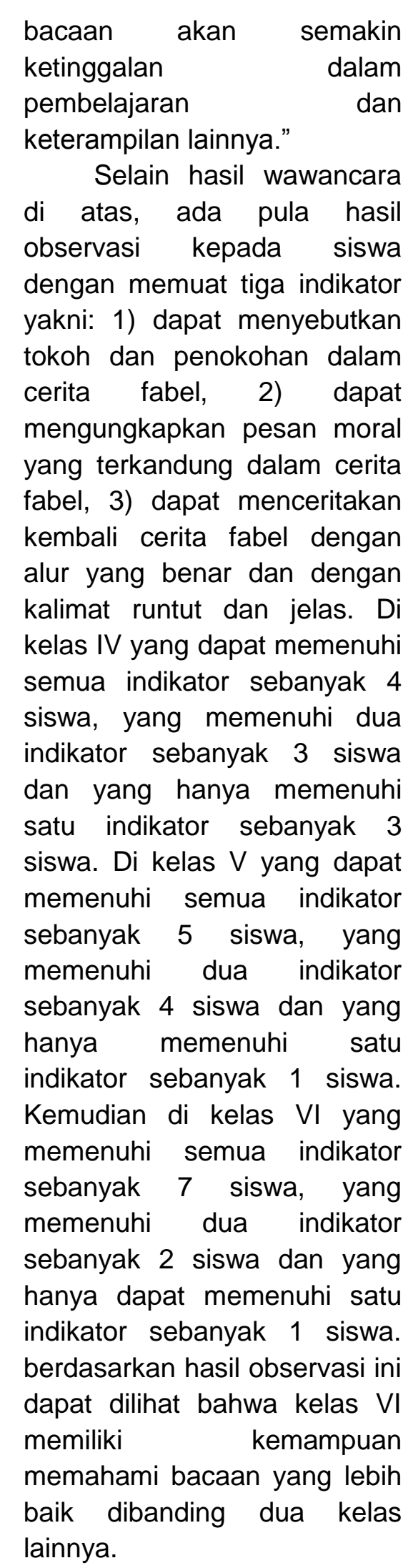

2) Peran Fabel dalam
Pembelajaran Mengenai peran fabel dalam pembelajaran yang diwawancarai sejumlah 33 responden, terdiri dari: 30 siswa dan 3 guru di kelas tinggi. Pada bagian ini akan dirangkum semua data menjadi satu kesatuan kemudian dianalisis berdasarkan teori yang berkaitan dengan fabel dalam pembelajaran. Perlu diketahui bahwa setiap butir-butir pertanyaan yang ada di daftar wawancara ke 30 responden yang terdiri atas siswa kelas tinggi didasarkan pada teori Majid (2005: 13) mengenai tujuan penggunaan fabel dalam pembelajaran.

30 responden yang terdiri dari siswa kelas tinggi mengakui bahwa mendengarkan cerita fabel adalah kegiatan yang menyenangkan dan menghibur. Mereka juga mengatakan bahwa fabel dapat menambah pengetahuan, ada yang menjawab melalui fabel mereka dapat belajar nilai-nilai kebaikan atau moral, hal yang sama juga diungkapkan oleh DB (guru kelas IV) bahwa melalui fabel anak dapat dididik mengenai etika dan nilai-nilai kebaikan. Sedangkan 2 responden menjawab dapat menambah pengetahuan tentang bahasa dan kosakata. Ketiga responden yang terdiri atas guru-guru kelas tinggi juga menyatakan bahwa fabel dapat meningkatkan kemampuan memahami bacaan terutama bagi 
anak-anak yang gemar membaca cerita-cerita fabel. JG (guru kelas VI) menambahkan bahwa fabel juga dapat digunakan untuk melihat kemampuan siswa dalam hal memahami bacaan. Seperti yang kita tahu bahwa biasanya dalam membaca fabel anak dituntut untuk bisa menemukan ide pokok setiap paragrafnya, memahami alur cerita dari cerita fabel tersebut, dan dapat menangkap pesan moral yang terkandung di dalam cerita fabel baik secara tersirat maupun tersurat. Hal di atas sejalan dengan yang diungkapkan Wahyu (2011: 176) sastra memiliki peran yang penting dalam perkembangan moral, sosial, dan psikologi. Dan ini yang menjadikan sastra khususnya fabel sangat relevan dalam pendidikan karakter anak (Wulandari, 2015: 67). Melalui cerita fabel dapat memudahkan guru maupun orang tua untuk menanamkan nilai kepribadian. Mengajarkan kepada anak untuk tidak sombong dan selalu rendah hati. Selain sebagai media menanamkan nilai-nilai moral kepada anak, fabel juga dapat memperluas kosakata dan pengetahuan bahasa anak. Semakin banyak membaca, semakin banyak tahu. Guru dapat menggunakan dongeng atau fabel sebagai media untuk mengenalkan kosa kata asing pada siswa yang pastinya akan berguna di masa depan (Majid 2005: 14-15).

Sekitar 24 responden mengaku bahwa saat membaca maupun mendengarkan cerita fabel, imajinasi mereka turut berperan. Sedangkan 6 responden lainnya mengaku tidak berimajinasi saat sedang membaca maupun mendengarkan cerita fabel. Hal yang sama juga diungkapkan oleh JG (guru kelas IV) bahwa fabel dapat digunakan sebagai bahan apersepsi agar anak dapat berimajinasi daam pembelajaran serta dapat juga menjaga kondisi emosional anak agar tidak mudah bosan. Hal ini menandakan, sebagian besar responden memiliki kemampuan untuk berimajinasi dan melalui fabel inilah kemampuan anak untuk berimajinasi dapat senantiasa diasah. Ini sesuai dengan pendapat Tarigan (2011: 7) sastra dapat mengembangkan imajinasi anak-anak dan membantu mereka mempertimbangkan dan memikirkan alam, insan, pengalaman, atau gagasan dengan berbagai cara. Karya sastra yang baik dapat membangkitkan rasa keingintahuan sang anak terhadap peristiwa yang terjadi di lingkungan hidup mereka.

Responden tersebut juga mengaku bahwa mereka menyukai tokoh-tokoh protagonis yang ada dalam cerita fabel karena dapat mengajarkan niali-nilai kebaikan kepada mereka, seperti jangan sombong, setia kawan, dan suka menolong. Melalui hal-hal inilah dapat mendidik akhlak siswa agar menjadi sebuah pedoman untuk berperilaku dalam kehidupan sehari-hari. Seperti yang diungkapkan oleh Tarigan (2011: 7) sastra dapat mengembangkan 
wawasan anak menjadi perilaku insani (human behavior).

Cerita fabel selain sebagai kegiatan yang menyenangkan dan menghibur,

menambahpengetahuan,

mengembangkan imajinasi, mendidik akhlak, disebut juga sebagai alat untuk mengasah rasa. Sebanyak 30 responden yang terdiri atas siswa ini mengatakan bahwa mereka dapat merasakan setiap emosi yang terkandung dalam cerita fabel dan kebanyakan dari mereka menyebut emosi bahagia yang sering mereka rasakan, sedangkan seorang lainnya menyebut rasa lucu atau humor yang terkandung dalam cerita yang paling banyak ia rasakan. Seperti yang kita tahu dalam setiap karya sastra, baik itu ceita fabel, dongeng, novel dan cerita pendek pastilah mengandung berbagai emosi yang diekspresikan setiap tokoh baik secara tersirat maupun tersurat. Melalui hal-hal inilah siswa diajarkan untuk mengenal berbagai jenis emosi yang sering mereka jumpai dalam kehidupan seharihari, baik di rumah, sekolah dan lingkungan masyarakat. $\mathrm{Hal}$ ini sejalan dengan yang dungkapkan Rukayah (2012: 10) bahwa karakteristik sastra sebagai bahan ajar relevan sekali dengan misi yang diemban oleh pengajaran bahasa Indonesia. Pengajaran bahasa Indonesia tidak hanya dimaksudkan untuk menumbuhkembangkan

kemampuan komunikasi anak didik, tetapi juga kemampuan berpikir dan bernalar, daya imajinatif, daya ekspresi, kepekaan emosi, dan memperluas wawasan anak. Misi yang demikian tentu sangat sulit untuk ditunaikan dengan hanya mengandalkan bahan ajar yang bersifat teknik dan ilmiah saja. Di sinilah letak kedudukan bahan ajar apresiasi sastra, yakni menunaikan misi yang tidak tertunaikan dengan bahan non-sastra.

Selain beberapa poin-poin di atas, ada beberapa butir pertanyaan tambahan yang disisipkan oleh peneliti terkhusus untuk 30 responden yang terdiri atas siswa di kelas tinggi yakni, seberapa sering fabel disisipkan dalam proses pembelajaran dan dalam hal ini 25 responden mengatakan pernah didongengkan fabel oleh gurunya di kelas lalu 5 responden lainnya mengatakan belum pernah.

\section{PENUTUP}

Kemampuan siswa memahami bacaan di kelas tinggi SD GMIH Paca, masih belum baik, karena mayoritas siswa hanya dapat memenuhi dua aspek membaca pemahaman. Sedangkan untuk aspek evaluasi dan dan kecepatan membaca yang fleksibel hanya dimiliki 2 - 8 siswa per kelasnya. Selain itu berdasarkan hasil observasi checklist, yang unggul dalam kemampuan memahami bacaan adalah kelas $\mathrm{VI}$ dan kelas $\mathrm{VI}$ inilah dimana cerita fabel sering didongengkan oleh sang guru 
dengan tujuan agar anak-anak memiliki ketertarikan untuk belajar.

Fabel sangat berperan untuk meningkatkan kemampuan siswa memahami bacaan, menanamkan nilai-nilai moral, menarik perhatian siswa untuk lebih fokus pada pelajaran dan dapat memperkenalkan berbagai bentuk emosi pada anak, seperti rasa bahagia, marah, kecewa, dan sedih. Melalui fabel juga kita dapat mengetahui di taraf mana kemampuan siswa dalam memahami bacaan karena biasanya dalam soal-soal yang berkaitan dengan fabel, siswa dituntut untuk memahami alur cerita fabel, ide pokok setiap paragraf dan pesan moral yang terkandung di dalamnya. Untuk menjawab setiap hal-hal tersebut dibutuhkan kemampuan mengevaluasi bahan bacaan, menyimpulkan, dan menangkap makna bacaan baik tersirat maupun tersurat.

\section{DAFTAR RUJUKAN}

Sari, A. S \& Pandjaitan, L. (2017). "Meningkatkan Kemampuan Memahami Bacaan Melalui Pelatihan Aspek Pemahaman Bacaan pada Siswa Kelas IV Sekolah Dasar. Prosiding Temu IImiah, hal: 146-153.

Tarigan, H. Guntur. (2015). Menulis Sebagai Suatu Keterampilan Berbahasa. Bandung: Angkasa.
Rosyada, D. (2004). Paradigma Pendidikan Demokratis. Jakarta: Kencana.

Somadoyo, Samsu. (2011). Strategi dan Teknik Pembelajaran Membaca. Yogyakarta: Graha IImu.

Maleong, Lexy (2009).MetodePenelitianKuali tatif. Bandung; RemajaRosdakarya.

Abdurrahman, Mulyono (2010). PendidikanbagiAnakBerkesul itanBelajar.Jakarta;

RinekaCipta.

Abdul, Majid (2005). PerencanaanPembelajaranM engembangkanStandarKomp etensi Guru.Bandung; RemajaRosdakarya.

Wahyu. (2011). Masalah dan Usaha Membangun Karakter Bangsa. Jurnal Komunitas 3(1): 138-179.

\section{Wulandari, E. (2015). Pembelajaran Sastra Berbasis Karakter. Jurnal Bahasa dan Sastra. 2(2): 157-167.}

Tarigan, H. G (2011).PrinsipprinsipDasarSastra.

Bandung; Angkasa

Rukayah. (2012). Pedoman Pelaksanaan Pembelajaran Sastra Anak dengan Pendekatan Koperatif di Sekolah Dasar. Surakarta: Universitas Sebelas Maret 